\section{International Scientific Journal Theoretical \& Applied Science}

p-ISSN: 2308-4944 (print) e-ISSN: 2409-0085 (online)

Year: 2017 Issue: $06 \quad$ Volume: 50

Published: $30.06 .2017 \quad$ http://T-Science.org

SECTION 6. Metallurgy and energy.
Bazartai Alimbayevich Alimbayev doctor of technical sciences,

Professor of the department «Building materials and constructions»»

M.Kh. Dulaty Taraz State University, Kazakhstan

Bauyrzhan Zharkynbekovich Manapbayev

Candidate of technical sciences, associate professor of the Department of «Oil and gas engineering»

M.Kh. Dulaty Taraz State University, Kazakhstan

Erkegali Nurgaliuly Amanbayev

PhD student,

M.Kh. Dulaty Taraz State University, Kazakhstan

\title{
COLLOIDAL PROCESSES IN THE DEVELOPMENT OF CORROSION OF STEEL IN METAL STRUCTURES OF HYDRAULIC STRUCTURE
}

Abstract: The ways of development of corrosion are examined in steel metallic constructions. One of variants of mechanism of development of corrosion offers in elements steel to the construction, taking into account their ferromagnetic properties.

Key words: corrosion, steel pipe, micelle, Lorentz's force.

Language: Russian

Citation: Alimbayev BA, Manapbayev BZ, Amanbayev EN (2017) COLLOIDAL PROCESSES IN THE DEVELOPMENT OF CORROSION OF STEEL IN METAL STRUCTURES OF HYDRAULIC STRUCTURE. ISJ Theoretical \& Applied Science, 06 (50): 173-176.

Soi: http://s-o-i.org/1.1/TAS-06-50-25 Doi: roskef https://dx.doi.org/10.15863/TAS.2017.06.50.25

\section{КОЛЛОИДНЫЕ ПРОЦЕССЫ ПРИ РАЗВИТИИ КОРРОЗИИ В СТАЛЬНЫХ МЕТАЛЛИЧЕСКИХ КОНСТРУКЦИЯХ ГИДРОТЕХНИЧЕСКИХ СООРУЖЕНИИ}

Аннотация: Рассматриваются пути развития коррозии в стальньх металлических конструкииях. Предложен один из вариантов механизма развития коррозии в элементах стальньх конструкиии, с учетом их ферромагнитных свойств.

Ключевые слова: коррозия, стальные конструкции, мицелла, сила Лоренца.

\section{Introduction}

Возможность развития коррозии в стальных конструкциях, находящихся длительное время в воде зависит от многих факторов. Причины коррозии стальных конструкций находящихся длительное время в водной среде полностью не определены. Природа сил, воздействующих на коррозию сталей в водной среде полностью не исследованы [1-4].

Здесь отражены наши исследования [5], которые были проведены в стальных конструкциях гидротехнических сооружений с учетом их ферромагнитных свойств. Как известно [6], в сталях постоянно существуют ферромагнитные свойства, которые влияют на их работу. Именно на эти свойства должным образом не было обращено внимание исследователями процесса коррозии.

С учетом последних исследований $[7,8]$ нами предлагается один из механизмов развития коррозии. Для проверки предложенного механизма развития коррозии нами проводятся эксперименты по изучению скорости развития коррозии [7], где была разработана установка для определения коррозии металла в стальных трубах под воздействием раствор поваренной соли $\mathrm{NaCl}$ $3 \%$. Раствор поваренной соли $(\mathrm{NaCl} 3 \%)$ был использован для получения результата, т.е. убыстрения скорости развитие коррозии. Результаты этих исследований показали интересные факты.

\section{Materials and Methods}

При коррозии стали необходимо учесть ферромагнитные свойства стали. Основной причиной активного протекания процесса коррозии заключается в том, что у стальных конструкций находящихся в воде на eе поверхности уменьшается число атомов, что влияет на процесс коррозии. Из-за чего на 
поверхности стальных конструкции за счет наносимых извне ударов и различных нагрузок начинают появляться трещины [9]. В свою очередь образовавшиеся трещины влияют на ферромагнитные свойства стали и разрушают доменные структуры [6] в них, изменяют магнитные свойства стали. Когда разрушается доменная структура стали, домены делятся на части, на конечных концах трещины образуются магнитные полюса [9], а между трещинами создается магнитное поле (рис.1).

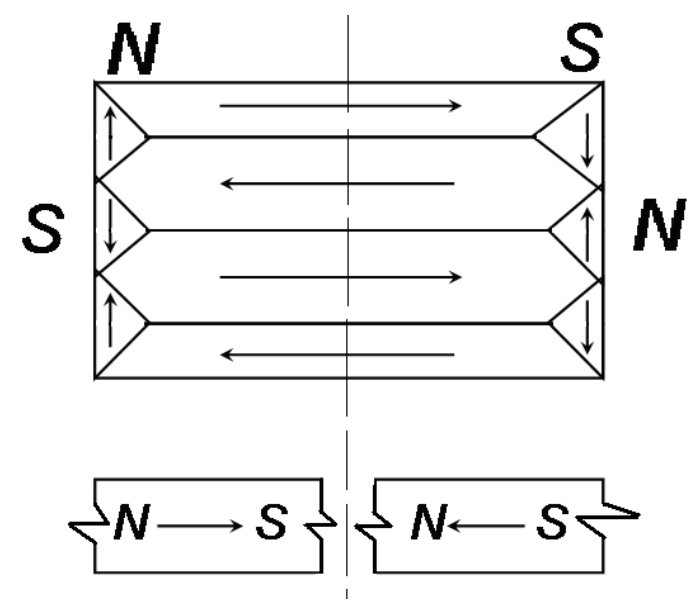

Рисунок 1 - Схема разрушения доменной структуры.

Когда разрушается доменная структура в сталях на ионы движущееся в водной среде действует сила Лоренца [10]

$$
\left.\vec{F}_{J}=q \cdot \mid \vec{v} \cdot \vec{B}\right]
$$

В коррозионной среде (вода, влага) присутствуют молекулы воды $\mathrm{H}_{2} \mathrm{O}$, ионы гидроксония $\mathrm{H}_{3} \mathrm{O}^{+}$и гидроксила $\mathrm{OH}^{-}$. Перемещение ионов в среде происходит по определенному механизму [11], который состоит в том, что между ионами гидроксония $\mathrm{H}_{3} \mathrm{O}^{+}$и молекулами воды, а также между молекулами воды и ионами $\mathrm{OH}^{-}$непрерывно происходит обмен ионами водорода $\mathrm{H}^{+}$. Под действием силы Лоренца [12] происходит разделение молекул, это способствуют дополнительному появлению между краями трещин ионов водорода $\mathrm{H}^{+}$и гидроксил-ионов $\mathrm{OH}^{-}$, то есть диссоциации воды (влаги).

На ионы $q$ движущиеся с определенной скоростью $v$ в магнитном поле $B$ действует сила Лоренца $F_{Л}$, которая старается повернуть ионы в перпендикулярном направлении. За счет силы Лоренца, действующей в этом магнитном поле, ионы натрии $\mathrm{Na}^{+}$и ионы хлорида $\mathrm{Cl}^{-}$будут притягиваться к краям трещины как к полюсам магнита (рис. 2).

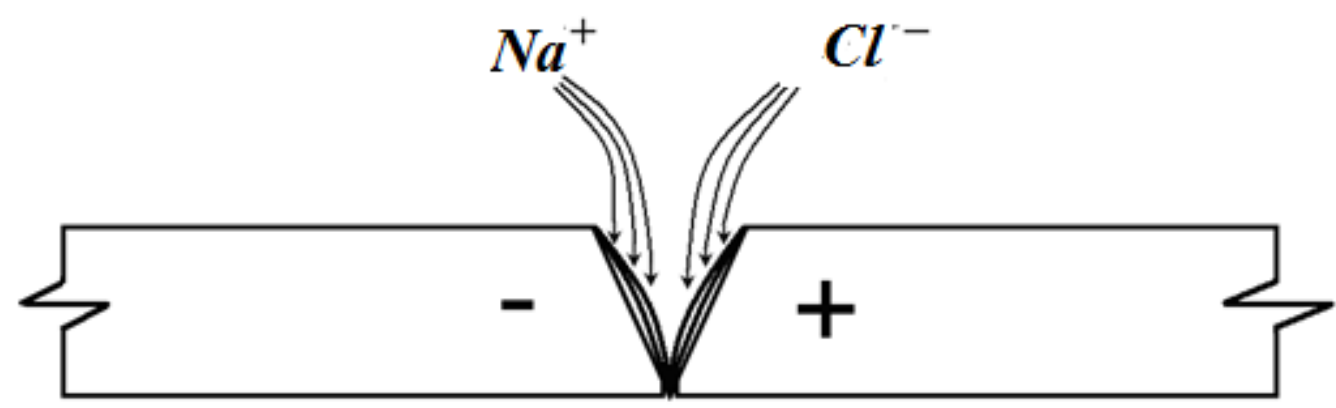

Рисунок 2 - Наполнение трещины доменной структуры ионами $\mathrm{Na}^{+}$және $\mathrm{Cl}^{-}$.

После прохождения физического процесса начинается химический процесс, т.е. реализуется этап развития трещин - их коррозионное зарождение. В трещине из-за недостатка кислорода активно протекает реакция

$$
\begin{aligned}
& \mathrm{Fe} \rightarrow \mathrm{Fe}^{2+}+2 \mathrm{e}^{-} \\
& \mathrm{Fe}^{2+}+2 \mathrm{Cl}^{-} \rightarrow \mathrm{Fe}(\mathrm{Cl})_{2} \\
& 2 \mathrm{Na}^{+}+2 \mathrm{e}^{-} \rightarrow 2 \mathrm{Na}
\end{aligned}
$$




\begin{tabular}{|c|c|c|c|c|c|c|}
\hline Impact Factor: & $\begin{array}{l}\text { ISRA (India) } \\
\text { ISI (Dubai, UAE } \\
\text { GIF (Australia) } \\
\text { JIF }\end{array}$ & $\begin{array}{l}=1.344 \\
=0.829 \\
=0.564 \\
=1.500\end{array}$ & $\begin{array}{l}\text { SIS (USA) } \\
\text { PИНЦ (Russia) } \\
\text { ESJI (KZ) } \\
\text { SJIF (Morocco) }\end{array}$ & $\begin{array}{l}=0.912 \\
=0.234 \\
=3.860 \\
=\mathbf{2 . 0 3 1}\end{array}$ & $\begin{array}{l}\text { ICV (Poland) } \\
\text { PIF (India) } \\
\text { IBI (India) }\end{array}$ & $\begin{array}{l}=6.630 \\
=1.940 \\
=4.260\end{array}$ \\
\hline
\end{tabular}

В результате химической реакции образуется хлорид железа (II), который создает пленку (рис. 3). Далее на развитие коррозии влияет образование коллоидных систем, состоящие из мицелл хлоридов железа, которые приводят к некоторому замедлению процесса коррозии.

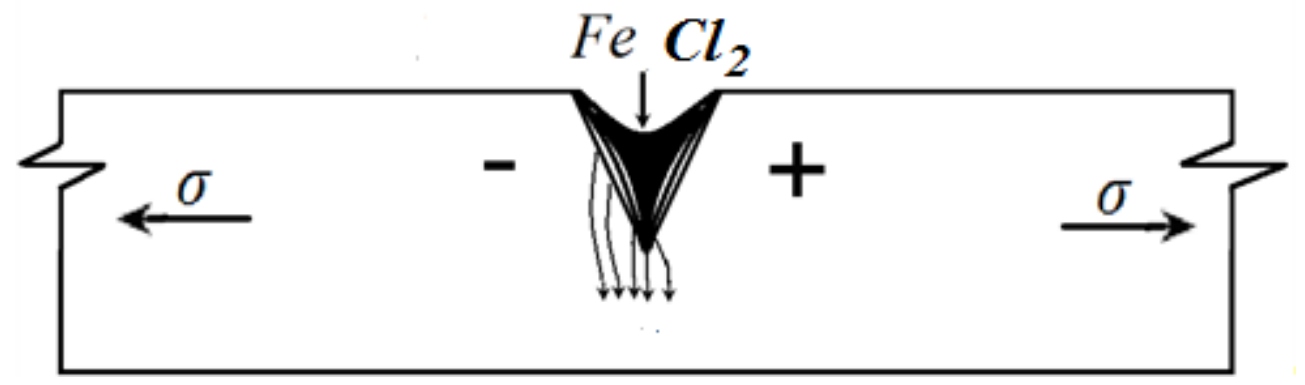

Рисунок 3 - Образованная пленка из хлорида железа (II) в трещине восстановление ионов натрия.

Коллоидные системы состоят из дисперсной фазы и дисперсионной среды. Частицу дисперсной фазы вместе с двойным электрическим слоем называют мицеллой [13] (Рис. 4). Далее рассмотрим примеры образование мицелл хлоридов железа.

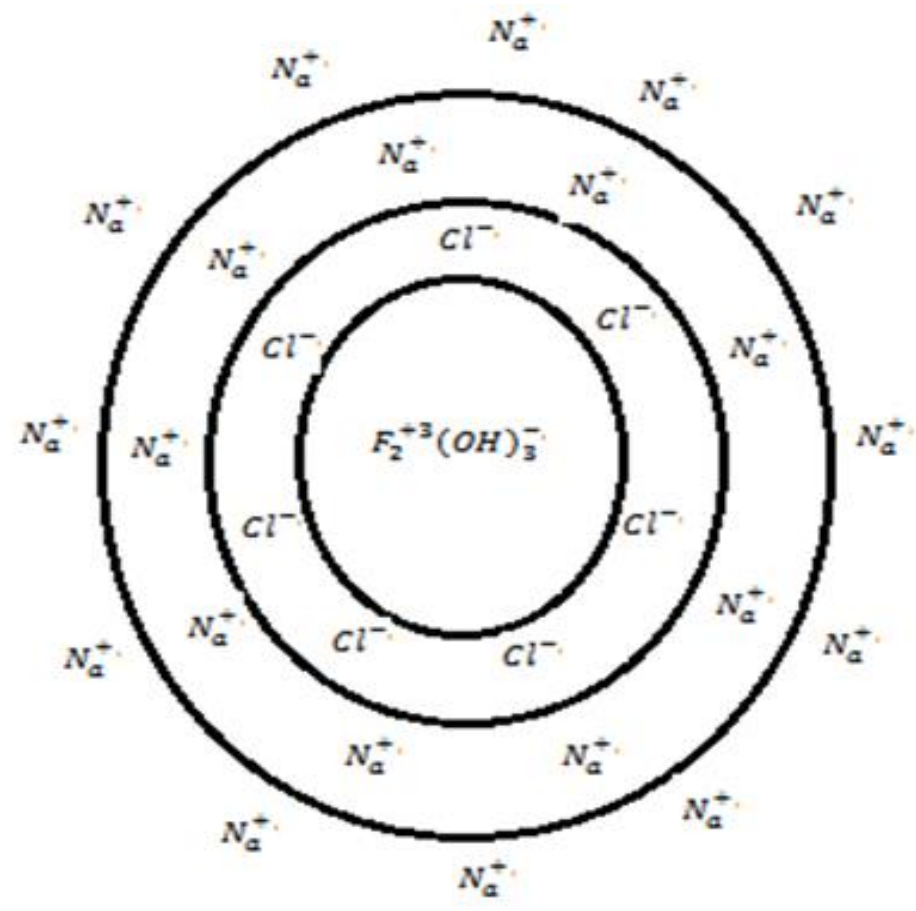

Рисунок 4 - Схематическое строение мицеллы золя хлорида железа.

Если действовать на хлоридный раствор железа (III) водой, повышая температуру, то он подвергается гидролизу. Происходят следующие изменения. Появляются коллоидные растворы [11]:

$$
\begin{gathered}
\mathrm{FeCI}_{3}+3 \mathrm{H}_{2} \mathrm{O} \rightarrow \mathrm{Fe}(\mathrm{OH})_{3}+3 \mathrm{HCI}, \\
\mathrm{Fe}(\mathrm{OH})_{3}+\mathrm{HCI} \rightarrow \mathrm{FeOCI}+2 \mathrm{H}_{2} \mathrm{O}
\end{gathered}
$$

Происходит мицельное соединение [11]. Создается плохо растворимый раствор $\mathrm{Fe}(\mathrm{OH})_{3}$ создается агрегат:

$$
\mathrm{Fe}(\mathrm{OH})_{3}+\mathrm{Fe}(\mathrm{OH})_{3} \rightarrow \mathrm{m} \mathrm{Fe}(\mathrm{OH})_{3}
$$

Находящаяся в растворе излишний заряд ионы электролита адсорбируются, поверхность агрегата заряжается, образуется ядро. В этом месте к агрегату притягиваются $\mathrm{Fe}^{3+}$ или $\mathrm{FeO}^{+}$: 


\begin{tabular}{l|lrl|l|ll} 
& ISRA (India) & $=\mathbf{1 . 3 4 4}$ & SIS (USA) & $=\mathbf{0 . 9 1 2}$ & ICV (Poland) & $=\mathbf{6 . 6 3 0}$ \\
Impact Factor: & ISI (Dubai, UAE) $=\mathbf{0 . 8 2 9}$ & PUHL (Russia) $=\mathbf{0 . 2 3 4}$ & PIF (India) & $=\mathbf{1 . 9 4 0}$ \\
& GIF (Australia) & $\mathbf{0 . 5 6 4}$ & ESJI (KZ) & $=3.860$ & IBI (India) & $=\mathbf{4 . 2 6 0}$ \\
& JIF & $=\mathbf{1 . 5 0 0}$ & SJIF (Morocco) & $=\mathbf{2 . 0 3 1}$ & & \\
\hline
\end{tabular}

$\mathrm{mFe}(\mathrm{OH})_{3}+\mathrm{nFeO}^{+} \rightarrow \mathrm{mFe}(\mathrm{OH})_{3} \cdot \mathrm{nFeO}^{+}$

С двух ионными слоями с гранулами коллоидных частиц дается формула (7):

$$
\begin{gathered}
\mathrm{mFe}(\mathrm{OH})_{3} \bullet \mathrm{nFeO}^{+}+(\mathrm{n}-\mathrm{x}) \mathrm{Cl}^{-} \rightarrow \mathrm{mFe}(\mathrm{OH})_{3} \\
\cdot \mathrm{nFeO}^{+}(\mathrm{n}-\mathrm{x}) \mathrm{Cl}^{-}
\end{gathered}
$$

где m-число молекул в мицельном агрегате $\mathrm{Fe}(\mathrm{OH})_{3}$; $\mathrm{FeO}^{+}$;

n - число ионов определяющих потенциал

(n-x) - число ионов адсорбционных слоях противоионы CI;

$\mathrm{X}$ - число ионов диффузионных слоях CI.

В этом случаи коллоидные частицы положительные заряды, поэтому n >> (n-x).

По закону нейтрального электричество заряда, запишется золь мицеллы по формуле (8)

$$
\left\{\mathrm{mFe}(\mathrm{OH})_{3} \cdot \mathrm{nFeO}^{+} \cdot(\mathrm{n}-\mathrm{x}) \mathrm{CI}^{-}\right\} \times \mathrm{CI}^{-}
$$

Можно записать положительные заряды коллоидных частиц. Например: при образовании золя гидроксида железы коллоидных частиц. В роли стаблизатора ҒеОСI.

$\mathrm{mFe}(\mathrm{OH}) 3$ - ядро мицеллы;

$\left\{\mathrm{mFe}(\mathrm{OH}) 3 \cdot \mathrm{nFeO}^{+} \cdot(\mathrm{n}-\mathrm{x}) \mathrm{CI}^{-}\right\}-$гранула, это адсорбционный слой;

хCI- -диффузионный слой.

\section{Conclusion}

Bce приведенные примеры составляют мицеллу. В итоге, можно утверждать, что образование мицелл хлоридов железа на микротрещинах поверхностей стальных конструкций в коррозионной среде влияет на скорость развитие коррозии. Данное утверждение не носит окончательный характер, так как исследование в этом направлений будут продолжены.

\section{References:}

1. Ulig GG, Revi RU (1989) Korroziya i bor'ba s ney. Vvedenie $\mathrm{v}$ korrozionnuyu nauku i tekhniku / Pod red. A.M. Sukhotina. - L.: Khimiya, 1989. - 456.

2. Tomashov ND (1959) Teoriya korrozii i zashchita metallov. - Moscow: Izd. AN SSSR, 1959. - 592 .

3. Karpenko GV (1985) Fiziko-khimicheskaya mekhanika konstruktsionnykh materialov. Izbr.tr. v 2-kh t. - Kiev: Nauk.dumka, 1985.- T. 1. -228 .

4. Evans YR (1941) Korroziya, zashchita i passivnost' metalla. - Moscow: Metallurgizdat, 1941. - 124.

5. Alimbaev BA, Manapbaev BZ (2012) Razvitie korrozii $\mathrm{V}$ elementakh metallicheskikh konstruktsiy v vodnoy srede. - Taraz: Taraz universiteti, 2012.-136.

6. Akulov NS (1939) Ferromagnetizm. - M.-L.: Gosizdat. tekhnicheskoy i teoreticheskoy literatury, 1939.

7. Amanbaev EN, Alimbaev BA, Manapbaev BZ (2016) Osobennosti razvitiya korrozii na uglakh povorotov $\mathrm{V}$ trubnykh stal'nykh konstruktsiyakh. - Almaty: Vestnik KazGASA, 2016.- №4.- p.71-75.

8. Amanbaev EN, Alimbaev BA, Manapbaev BZ (2016) Issledovanie vliyaniya ferromagnitnykh svoistv na razvitie korrozii $\mathrm{v}$ stal'nykh konstruktsiyakh. - Astana: Vestnik ENU, 2016.- №6.- p.168-172.

9. Gorazdovskiy TY (1977) Nerazrushayushchiy kontrol'.- Moscow: Znanie, - 64.

10. Savel'ev IV (1970) Kurs obshchey fiziki. Elektrichestvo. - Moscow: Nauka, 1970. - T.2.432.

11. Stromberg AG, Semchenko DP (2001) Fizicheskaya khimiya. Ucheb. dlya khim. spets. vuzov. Pod redaktsiey A.G.Stromberga. - 4-e izd. ispr. - Moscow: Vyssh. shk., 2001. - 527.

12. Branover GG, Tsinober AB (1970) Magnitnaya gidrodinamika neszhimaemykh sred. - M.: Glavnaya redaktsiya fiziko-matematicheskoy literatury izdatel'stva «Nauka», -380 .

13. Belik VV, Kienskaya KI (2007) Fizicheskaya i kolloidnaya khimiya. - M.: Akademia. 2007. 